\section{Essential Information about Predatory Publishers and Journals}

JefFrey BeALL

Jeffrey Beall is associate professor and scholarly communications librarian, Auraria Library, University of Colorado Denver, Denver, Colorado, US.E-mail: jeffrey.beall@ucdenver.edu.

$\mathrm{M}$ y first experience with predatory publishers was in 2008, when I began to receive strange e-mailsmostly from South Asia-inviting me to submit research manuscripts to journals I had never heard of before. The spam e-mails had headlines like "Call for Paper," which is incorrect English. What surprised me the most was that the journals' Web sites stated that they charged authors to publish in the journals, a radical change from subscription journals, in which authors were not charged to publish.

The e-mails signaled to me the beginning of gold openaccess publishing. In gold open access, the publishing costs are covered by fees charged to the authors upon acceptance of their manuscripts for publication. The advantage of this publishing model is that the published articles are free for anyone to access.

Although some non-profit scholarly societies have used "page charges" to subsidize publishing costs, the large-scale practice of requiring authors to cover these costs began with the proliferation of for-profit, gold open-access journals around 2008.

While open access (OA) was initially promising, its weaknesses quickly began to appear. Publishers soon realized that they could make more money from author fees if they accepted more papers. Peer review began to be seen as a threat to a publisher's income, because when it is conducted properly, papers are often rejected for publication. Rejection means the loss of revenue for publishers using the gold OA model.

Accordingly, many gold open-access publishers began to perform only cursory peer reviews, accepting most papers submitted and pocketing the fees paid by the authors. Now, they typically do everything they can to trick authors into submitting papers in order to get the author fees from them. So, by definition, predatory journals and publishers are those that exploit the gold open-access model to profit from scholarly publishing in a dishonest way.

Indeed, predatory publishers are dishonest, they lack transparency, and they do not follow scholarly publishing industry standards. Many of them misrepresent their true headquarters locations, claiming they are based in London or New York when they are really based in Pakistan or India.

I already mentioned their practice of spamming, and this has reached epidemic proportions, with researchers sometimes receiving several spam e-mails from scholarly publishers every hour. Publishers using the gold open-access model especially target researchers with grant money, for these funds can be used to pay article processing charges. Thus, authors in the biomedical sciences, where grants are more common, are frequently targeted by predatory journals.

\section{Why They Are a Problem?}

Predatory publishers hurt scientists, science, and the communication of science. As mentioned, they trick scientists, pretending to operate as legitimate publishers, when they are essentially counterfeit and only seeking to earn a quick profit. Busy scientists often lack time to sufficiently investigate a publisher and can mistakenly submit a paper to one of their journals or accept an editorial board invitation.

Low quality journals pollute science with junk science and unvetted research. Some scholarly databases aim to have a broad coverage of journals and include these predatory journals in their indexes. One example is Google Scholar, which indexes articles from hundreds of low-quality and predatory journals.

Researchers preparing literature reviews are faced with databases that include junk journals in them, so they have to carefully select whether a given article should be cited or not. Moreover, students frequently use these databases, but they lack the experience and credentials to sort out the authentic science from the junk science.

Junk science is also called pseudo-science, and it represents theories and conclusions that cannot be supported by science-based research. Many political activists are now using predatory journals to publish their ideas as science. For example, anti-nuclear activists write articles making nuclear energy appear more dangerous that the data really indicates. Also, people creating medical compounds, such as new drugs, now regularly write articles in predatory journals that "find" that the drugs they invented are very effective.

\section{COMPLICIT AUthors}

Sometimes, scholarly authors take advantage of the easy publishing that predatory journals offer for their own benefit. In many cases, universities base faculty evaluations and promotions only on the number of articles published, and they do not distinguish between high quality and predatory journals. It is pretty easy to write up a scholarly article and get it quickly published in a predatory journal. Here the victims are the honest researchers, those who submit their 
work to selective scholarly journals, where it is more difficult to publish and the process is slower. Increasingly, there are predatory publishers that specialize in quick, easy, and cheap publishing.

\section{Approved SCHolarty INDEXes}

Many universities base their evaluation on faculty publications in journals included in prestigious indexes, such as Web of Science or Scopus. This "whitelist" approach is not without its flaws, as the indexes sometimes make mistakes and include easy-acceptance, pay-to-publish journals. In some cases, respected journals cannot resist the temptation to generate much revenue, so they lower their standards, accepting most submitted papers.

\section{Predatory publishers hurt scientists, science, and the communication of sci- ence.}

\section{Geographic Focus}

Predatory publishers have been more successful in some regions of the world than in others. One broad area that has seen many victims of predatory journals is Eastern Europe, the former Soviet republics, and Russia. In these regions, academic evaluation is often based merely on counting the number of papers published. This matches perfectly with predatory journals, who offer quick, easy, and cheap publishing. Many researchers submit papers to predatory journals but fail to realize they are counterfeit journals. Their work is quickly accepted and published, and they soon receive an invoice, usually an unexpected one, from the publisher.

When a few predatory journals invade a region and become successful at attracting articles and payments from researchers, others quickly follow. Then the number of publishers multiplies, and the number of spam e-mails grows also. We are now beginning to see low-quality and predatory open-access publishers being established in Eastern Europe and the former Soviet republics.

\section{IDentifying Predatory Journals}

The characteristics of predatory journals are becoming well known. As mentioned, predatory journals use spam e-mail to solicit articles, they have a fast and often fake peer review process, and they supply false information about their locations. Many now also make false claims about having impact factors or being included in prestigious academic indexes. Now it is important to verify all claims made by open-access journals, for many are dishonest.

The lists I publish also identify predatory journals and publishers, and many researchers find them useful. These lists are found at <scholarlyoa.com>. Compiled with the help and advice of many active researchers, the lists include publishers and journals that ought to be avoided by honest researchers.

\section{LONG-TERM ViEW}

While publishing one's research in a predatory journal may bring temporary gain, the long-term consequences are likely to damage a researcher's reputation. It is not uncommon for predatory journals to disappear from the Internet after several years. Most are one-man operations, and the published articles have no backups. Researchers may be stigmatized for publishing in easy-acceptance, pay-to-publish journals. Potential employers may reject applicants who have published articles in predatory journals.

For all researchers, the best course of action is to avoid predatory journals. Carry out high-quality research and submit it to the best possible journals. This strategy is more difficult and time-consuming, but it eliminates the risks predatory journals bring and offers researchers better and more secure long-term benefits.

Editor's note: An earlier version of this article was published in the journal Higher Education in Russia and Beyond—v. I, no. 7 (2016), p. 77-79.

\section{International Doctoral and Master's Students: What the Data Tell Us}

\section{Gabriele Marconi}

Gabriele Marconi is analyst at the Directorate for Education and Skills in the Organisation for Economic Co-operation and Development (OECD). E-mail: gabriele.marconi@oecd.org.

Curreve urrently, one in ten students at the master's or equivalent level is an international student in OECD countries, rising to one in four at the doctoral level, according to data from the UNESCO-OECD-Eurostat data collection referring to 20I3. In Luxembourg and Switzerland, international students make up more than half of the total doctoral enrollment. 